\title{
Nutrición y refugiados
}

\author{
Pilar Torre \\ Consultora en Nutrición de UNICEF
}

\section{Resumen}

El presente trabajo describe las condiciones demográficas y de nutrición, salud y vivienda que se detectaron entre los refugiados guatemaltecos cuando, en 1982, se inicia el gran movimiento migratorio hacia el estado de Chiapas. Aunque en México no existe el estatus legal de refugiados, esta forma que asume la migración en donde la población es expulsada de manera violenta de su país de origen en busca de asilo bien podría entrar en la definición de refugiados. Se hace énfasis en las condiciones de nutrición de los menores de seis años en uno de los campamentos localizados en la ribera del río Lacantún, en la zona selvática de Marqués de Comillas, Municipio de Ocosingo, Chiapas. La información aquí presentada surge de la experiencia de campo obtenida al desarrollar el Programa de Alimentación Complementaria a Grupos Vulnerables. Este artículo no pretende describir el marco histórico de este fenómeno migratorio, sin embargo, algunos datos son de interés para situar el presente estudio.

Palabras clave: refugiados guatemaltecos, migración centroamericana, nutrición infantil, desnutrición, Programa de Alimentación Complementaria.

\begin{abstract}
This job describes the health, demographical, and housing conditions detected among the Guatemalan refugees when the great migratory movement started towards the state of Chiapas in 1982. Mexico does not have legal statutes for refugees; however, migration assumes this form based on the fact that people are defined as refugees when they are violently expelled from its country looking for asylum. It specifically emphasizes the nutritional conditions of children under six years old at one of the refugee camps located by the river Lacantún, in the jungle zone of Marqués de Comillas, Municipality of Ocosingo, Chiapas. The information herein contained is the result of field experiences while developing the Program for Complementary Feeding to Vulnerable Groups. This article does not mean to describe the historical frame of this migratory phenomenon; however, most of its information is interesting to locate this research.
\end{abstract}

Keywords: Guatemalan refugees, Central American migration, child nutrition, undernourishment, Program for Complementary Feeding. 


\title{
NUTRICION Y REFUGIADOS
}

\author{
Pilar Torre ${ }^{*}$
}

\section{INTRODUCCION}

El presente trabajo describe las condiciones de nutrición, salud, sivienda y demográficas que se encontraron en los refugiados guatemaltecos cuando, en 1982, se inicia el gran movimiento migratorio hacia el estado de Chiapas. Se refiere en particular a las condiciones de nutrición de los menores de seis años en uno de los campamentos localizado en la ribera del río Lacantún, en la zona selvática de Marqués de Comillas. Se presentan los datos sobre el estado de nutrición de los niños refugiados en dos períodos: diciembre de 1982, fecha en que inició el programa de atención nutricional, y abril de 1983, a cuatro meses de distancia. Se discuten algunos puntos de interés en lo que a la atención nutricional de las personas desplazadas se refiere, y se definen las actividades llevadas a cabo para proporcionar atención nutricional a los grupos vulnerables de refugiados guatemaltecos. La información que aquí se presenta surge de la experiencia de campo que se obtuvo al desarrollar el Programa de Alimentación Complementaria a Grupos Vulnerables, y no responde a un proyecto de investigación específico.

El objetivo de este artículo no es describir el marco histórico de dicho fenómeno migratorio, sin embargo, algunos datos son de interés para situar el presente estudio.

A partir de marzo de 1982, en la zona fronteriza del estado de Chiapas, se produce un fenómeno migratorio totalmente diferente al usual en la región. Tradicionalmente, la población agrícola guatemalteca cruzaba la frontera durante ciertas épocas del año para trabajar en la recolección del café, en la zafra, en el comercio y otros intercambios. En esta área limítrofe las culturas indígenas tienen gran similitud y los pueblos hacían poco caso de las fronteras. Pero al

- Nutrióloga. Consultora en nutrición de UNICEF, 1982-1986. Los postulados básicos de este trabajo fueron presentados en el Symposium de Servicios de Salud para Refugiados y Desplazados en el Centro Médico de la Universidad de Georgetown, Washington, D.C., del 4 al 7 de diciembre de 1988. 
agudizarse la acción militar en Guatemala, México significó la diferencia entre la vida y la muerte, por lo que alrededor de 100,000 personas cruzaron la frontera.

Aunque en México el estatuto legal de refugiados no existe, se considera que esta forma que asume la migración en donde la población es expulsada de manera viclenta de su país de origen para buscar asilo en el país receptor, debía ser considerada dentro de la definición de refugiados.

El primer gran flujo de refugiados tuvo lugar en marzo de 1982. Posteriormente, a finales de septiembre ydurante el mes de octubre del mismo año, se produjo una migración aún mayor. Durante 1983 y 1984 la llegada de guatemaltecos a territorio mexicano continuó de manera constante, pero en mayor número. Para marzo de 1984 se reconoció oficialmente la existencia de 89 campamentos con una población total aproximada de 42,000 refugiados. Se señala como campamento la modalidad que toma el asentamiento de refugiados. Para el caso de los guatemaltecos en el estado de Chiapas, los campamentos van desde pequeños grupos de 6 familias hasta el mayor de 4,000 habitantes. Estos asentamientos se localizaron en los siguientes municipios de la zona fronteriza del estado de Chiapas: Margaritas, Trinitaria, Ocosingo, Independencia y Frontera Comalapa. En mayo de 1984 el ejército guatemalteco incursionó el territorio mexicano por medio de una acción violenta en el campamento de Chupadero, municipio de Trinitaria. Esta acción puso de manifiesto la inseguridad y el riesgo en el que se encontraban los refugiados en los campamentos ubicados tan cerca de la frontera; por tanto, el gobierno mexicano tomó la decisión de reubicar a los refugiados en los estados de Campeche y Quintana Roo y para finales de 1985, aproximadamente el $50 \%$ de los refugiados fueron reubicados en dos grandes campamentos en Campeche y dos en Quintana Roo.

La situación política, económica y militar por la que atraviesa América Central, agudizada desde finales de los años setenta, generó este fenómeno migratorio, el cual se ha vuelto una constante. Estos fenómenos están mostrando la patología (las enfermedades) determinada por la represión, la cual adquiere características particulares. La alta presencia de desnutrición de tercer grado de tipo agudo (Kwashiorkor), la elevadísima mortalidad infantil y preescolar, e 
inclusive el miedo, señalan panoramas cpidemiológicosinteresantes de destacar.

Por la magnitud de este fenómeno migratorio, por su impacto, económico, político y social en uno de los estados del país con mayor marginación, por la inexperiencia del gobierno mexicano para afrontar un fenómeno de tal trascendencia e inusitado en la historia nacional, la situación de los refugiados se abordó como una emergencia.

\section{PROGRAMA DE ALIMENTACION COMPLEMENTARIA A GRUPOS VULNERABLES}

\section{ANTECEDENTES}

Desde mayo de 1982, el Hospital Regional "C" de laSecretaría de Salud en Comitán, Chiapas, detectó los problemas de salud de los refugiados, ésto debido no sólo al incremento de enfermos hospitalizados de origen guatemalteco, sino a que dicho hospital tiene programas extramuros y su capacidad de atención fue ampliamente rebasada. Simultáneamente, dos organismos de las Naciones Unidas: el Alto Comisionado de Naciones Unidas para Refugiados (ACNUR) y elFondo de Naciones Unidas para la Infancia (UNICEF) comenzaron a prestar apoyo técnico y financiero a través de la Comisión Mexicana de Ayuda a Refugiados (COMAR), organismo que formalmente involucra a tres Secretarías de Estado: Gobernación, Relaciones Exteriores y Trabajo y Previsión Social.

Dado que las condiciones de salud de los refugiados eran alarmantes y con el objeto de utilizar planificada yeficientemente los recursos, en octubre de 1982 se realizó un taller para generar el Proyecto de Asistencia, Salud, Nutrición y Saneamiento para refugiados guatemaltecos en el estado de Chiapas. La sede de esta reunión fue la oficina de UNICEF en México. Hubo participantes de las siguientes instituciones: ACNUR, UNICEF, Organización Panamericana de la Salud (OPS), y COMAR, Promoción del Desarrollo de Chiapas (PRODECH), Servicios Coordinados de Salud Pública en el estado de Chiapas y Hospital General "C" de la Secretaría de Salud.

Los objetivos fundamentales de dicho proyectoestaban orientados a disminuir la morbilidad (la frecuencia de las enfermedades) y la 
mortalidad por desnutrición y enfermedades infecciosas en los grupos de refugiados, a través de cinco acciones específicas: la dotación de alimentos familiares, la atención nutricional, la asistencia médica, la vacunación y el saneamiento ambiental con participación comunitaria.

Los trabajos publicados sobre atención de la salud a personas desplazadas se refieren en gran parte a los casos de emergencias ocasionados por los desastres naturales. Los mismos se inclinan hacia la vigilancia epidemiológica de las enfermedades infecciosas y es notoria la escasa información respecto al manejo de los programas especiales de alimentación. Por otra parte, los problemas de nutrición que originan los desastres naturales se presentan bruscamente, puede no existir una situación de desnutrición previa y la emergencia es temporal. En cambio, en el fenómeno que nos ocupa, tenemos una población con desnutrición crónica, en una situación que se ha desarrollado lentamente y donde la permanencia en el país de asilo es prolongada.

La organización Mundial de la Salud (OMS), la OPS, el Comité Internacional de la Cruz Roja, el UNICEF, el ACNUR y otras instituciones que han intervenido en situaciones de emergencia o de desastres, señalan la necesidad de dar prioridad no sólo al abastecimiento oportuno y organizado de alimentos familiares, sino a los programas especiales para grupos vulnerables, ya que un estado de nutrición deficiente determina la alta incidencia (frecuencia de casos nuevos) de las enfermedades y su severidad.

Se definen como grupos vulnerables a los niños menores de cinco años, a las mujeres en período de embarazo o de lactancia, los enfermos, los ancianos y aquellos niños mayores de cinco años identificados como desnutridos; todos los antes mencionados son vulnerables a padecer desnutrición porque sus demandas fisiológicas de nutrientes son relativamente mayores que las del resto de la población. Para dar atención nutricional especial a los grupos vulnerables, se les proporcionaría una ración de atole de $250 \mathrm{ml}$.; a los niños de 6 meses a 1 año se les daría además $150 \mathrm{~g}$. de papilla o colado y se administrarían también suplementos de vitaminas y hierro.

Hubo necesidad de ampliar las actividades propuestas en el proyecto inicial, debido a las condiciones críticas de nutrición y salud 
en que se encontraba la población. En todo momento las intervenciones en nutrición iban junto con las labores de investigación y de capacitación a la comunidad y se retroalimentaban entre sí.

El propósito de los programas especiales para grupos vulnerables es el de disminuir las deficiencias de energía, proteínas, vitaminas y hierro en la dieta consumida. Este tipo de programa se justifica ya que la desnutrición energético-protéica, aunada a las anemias severas de orígenes múltiples y a las avitaminosis, son quizá el problema de salud más importante durante una emergencia prolongada como la presente. Vinculados al programa de alimentación complementaria a grupos vulnerables se encuentran la evaluación y la vigilancia del estado de nutrición de la población, que son otras de las actividades indicadas durante este tipo de emergencias. Las razones para evaluar el estado de nutrición en los programas de socorro, se deben a que permiten determinar las prioridades en la distribución de la ayuda y obtener información sobre el efecto de los programas de intervención.

La vigilancia epidemiológica, entendida ésta como la evaluación y seguimiento sistemáticos del estado de nutrición, contribuye a la atención preventiva y a la promoción de salud porque ayuda a:

- Identificar a los niños desnutridos y a pronosticar el riesgo de mortalidad y morbilidad, con el fin de disminuir el daño y prevenir la muerte;

- Capacitar a los miembros de la comunidad (comités de salud) para que decidan la alimentación que debe suministrarse a los niños más vulnerables y para que recomienden otras intervenciones con mayor exactitud;

- Proporcionar datos confiables que permitan evaluar las intervenciones específicas, así como el impacto del programa global y seguir de cerca el progreso regional y local;

- Enseñar a las familias, mediante su participación en la vigilancia del estado de nutrición, la manera en que la alimentación afecta l. salud motivándolas para lograr mejoras en su dieta diaria; 
- Permitir que la población participe en la toma de decisiones y lleve a cabo iniciativas de acción preventiva.

Al producirse una catástrofe naturalgrave, la mortalidad puede ser muy grande al principio, pero la desnutrición no constituye un problema salvo que la situación de nutrición previa haya sido deficiente o nose adopten enseguida medidas adecuadas de asistencia. En cambio, las situaciones que se desarrollan con lentitud, cuando afectan una población que padece desnutrición crónica, originan una elevación gradual del número de defunciones por el aumento en la incidencia de la desnutrición. Si bien la muerte es la consecuencia final, y, por lo tanto uno de los indicadores más rudimentarios en un diagnóstico de salud, las tendencias de la mortalidad en el tiempo pueden indicar la gravedad de la situación y su efecto sobre la población.

\section{SITUACION GENERAL}

Para tener un primer diagnóstico de las condiciones de nutrición, se realizó una visita en noviembre de 1982 a diversos campamentos. Se determinó que los ubicados en la zona selvática de Marqués de Comillas, municipio de Ocosingo, eran prioritarios debido a la reciente y masiva llegada de refugiados, a las dificultades en la comunicación y a los serios problemas de tipo logístico para el abastecimiento de alimentos y medicinas.

Los campamentos atendidos en un principio en lo que se refiere al Programa de Alimentación Complementaria a Grupos Vulnerables fueron: Puerto Rico, con una población aproximada de 4000 refugiados; Ixcán, con 1400, y Chajul con 1200 en diciembre de 1982. La forma de acceso desde Comitán es por avioneta, como el medio usual de comunicación en la región en un vuelo de aproximadamente una hora. Los tres campamentos contaban con una pequeña pista de aterrizaje de tierra desmontada y apisonada. Estos se comunicaban entre sí por vía fluvial a través del río Lacantún. La región es selvática tropical, calurosay con una gran precipitación pluvial $(5000 \mathrm{~mm} / \mathrm{año})$. Aún en las épocas de secas, las lluvias son frecuentes y la zona queda aislada de los centros urbanos.

El campamento que se identificó como prioritario fue Puerto Rico y por ello las actividades comenzaron ahí. Esto se decidió porque era 
cl más poblado, por las apremiantes condiciones de salud y de nutrición detectadas, porque en el improvisado panteón había 32 tumbas y porque morían de 2 a 3 niños por día en una población de 4000 habitantes aproximadamente. Se pensó que era más importante comenzar con estos datos que esforzarse por obtener cifras cuantitativas precisas, ya que esta precisión puede alcanzarse con el transcurso del tiempo.

Puerto Rico estuvo habitado por una sola familia mexicana hasta febrero de 1982, en marzo llegaron al paraje alrededor de 700 personas y posteriormente, más de 3000 refugiados arribaron a la localidad. Estos provenían de los departamentos de Huehuetenango y del Quiché, en su mayoría eran indígenas de la familia Maya-Quiché. Hablaban seis diferentes lenguas: Kanjobal, Mam, Quiché, Kalkchiquel, Chuj y Kekchí. La mayor parte de los hombres comprenden y hablan el español; no así las mujeres que, se puede decir, eran monolingües. Existía un elevado grado de analfabetismo y generalmente los pocos que sabían leer y escribir eran hombres.

La forma de organización social que adoptaron al llegar a México fue un reflejo de la organización de cooperativas de producción que tenían en Guatemala. Se conformaron siete grupos de población de acuerdo con el lugar de procedencia. Cada uno de los grupos eligió a dos representantes generales, así como a las personas encargadas de desarrollar actividades específicas en salud, educación, construcción de viviendas y otras. Las funciones de los representantes eran múltiples: conocían a la población y la ubicación de las familias en cl campamento, elaboraban censos, repartían alimentos e intervenían en la planificación y ejecución de obras como la pista de aterrizaje, la clínica, la escuela, el comedor y los caminos y puentes vecinales.

En un principio, las condiciones de las viviendas eran muy malas, los techos eran de plástico, las personas dormían en el suelo bajo los árboles presentando un alto grado de hacinamiento. Posteriormente se desmontó más terreno y se construyeron casas utilizando materiales de la zona; éstas tenían una sola habitación que consideraba también la cocina. Los alimentos se preparaban en fogones a nivel del piso y los utensilios de cocina eran muy escasos, en especial los molinos de nixtamal. Su alimentación se basaba en el maíz y el frijol, pero acostumbraban también el consumo de frutas y verduras. La mayoría 
vestía sus trajes tradicionales pero contaban con muy poca ropa y '“" malas condiciones. Calzaban botas de hule y la mayor parte de l:1: mujeres y los niños estaban descalzos.

El trabajo de la mujer era intenso, tenía la responsabilidad de preparar los alimentos familiares, moler el maíz, acarrear el agua y l: leña, lavar la ropa y los utensilios y cuidar a los niños. El agua para uso doméstico se tomaba de un arroyo de aguas claras y corrientes, localizado a unos 200 metros del centro del poblado. La población tenía idea de la utilidad de hervir el agua, pero esta práctica no se llevaba a cabo en parte por la carencia de utensilios de cocina y de almacena mientoy por el gasto de combustible. En lo relacionado con las letrinas, había serios problemas técnicos difíciles de resolver por lo pantanoso del terreno.

Las enfermedades más comunes eran: desnutrición energéticoprotéica, paludismo, tuberculosis, uninariasis y otras parasitosis, anemia severa, gastroenteritis y enfermedades respiratorias.

Su alimentación dependía exclusivamente de la ayuda recibida. Los recursos financieros para proveer de alimentos a los refugiados provenían de las organizaciones internacionales, principalmente del ACNU. Los alimentos recomendados para esta población se ilustran en el siguiente cuadro.

CUADRO 1. Consumo diario recomendado por persona calorías y proteínas.

\begin{tabular}{lccc}
\hline \multicolumn{1}{c}{ Alimento } & $\begin{array}{c}\text { Cantidad } \\
(\mathrm{gr})\end{array}$ & $\begin{array}{c}\text { Energía } \\
(\mathrm{Kcal})\end{array}$ & $\begin{array}{c}\text { Proteínas } \\
(\mathrm{gr})\end{array}$ \\
\hline Maíz & 300 & 1050 & 24.9 \\
Frijol & 100 & 332 & 19.2 \\
Azúcar & 50 & 192 & -- \\
Arroz o avena & 40 & 145 & 2.9 \\
Pescado seco & 40 & 149 & 32.7 \\
Zanahoria o papa & 60 & 20 & 0.6 \\
Sal & 5 & - & -- \\
\hline TOTAL & 623 & 2135 & 80.3 \\
\hline
\end{tabular}


El cuadro 2 muestra que la dotación de alimentos familiares era insufuciente en diciembre de 1982. Con base en lo recomendado por el Instituto Nacional de Nutrición, el déficit de calorías por persona, por día, era de $87.5 \%$ y el de proteínas $90.8 \%$. Esto se debía en gran parte a la constante llegada de refugiados, a lo incomunicado de la zona, a la ausencia de bodegas regionales de almacenamiento y a la falta de experiencia del personal de campo de la COMAR en el manejo de este tipo de situaciones.

CUADRO 2. Alimentos diarios recibidos por persona calorías y proteínas diciembre 1982.

\begin{tabular}{lccc}
\hline Alimento & $\begin{array}{c}\text { Cantidad } \\
(\mathrm{gr})\end{array}$ & $\begin{array}{c}\text { Energía } \\
(\mathrm{Kcal})\end{array}$ & $\begin{array}{c}\text { Proteínas } \\
(\mathrm{gr})\end{array}$ \\
\hline Maíz & 54 & 189 & 4.5 \\
Frijol & 10 & 33 & 1.9 \\
Arroz & 13 & 47 & 1.0 \\
\hline TOTAL & 77 & 269 & 7.4 \\
\hline
\end{tabular}

La estructura demográfica de esta población presenta ciertas características que están determinadas por este fenómeno migratorio particular. Con base en los datos demográficos obtenidos a partir de los censos locales, se supo que el $27.7 \%$ de la población total lo constituían los menores de 6 años. En México, este grupo de edad representa el $20 \%$. Se puede decir que es una población joven, ya que los menores de 15 años constituyen el $58.0 \%$ de la población (para México y Guatemala este grupo de edad lo integra el $47.9 \%$ y el $45.4 \%$ respectivamente) y tiene una elevada proporción de menores de un año $(5.6 \%)$, cifra significativamente mayor que la encontrada para México y para el estado de Chiapas, ambos con el $3.9 \%$. En promedio, el número de miembros por familia es de 5.2 , cantidad que para la población mexicana en 1980 fue de 4.8 . 
NUTRICION Y REFUGIADOS

\section{ALGUNOS RESULTADOS DE LA EVALUACION DEL ESTADO I)। NUTRICION}

\section{Consideraciones metodológicas}

El análisis del estado de nutrición y la mortalidad de los preesco lares han sido reconocidos como los indicadores que evidencian más claramente la relación salud-sociedad. Alpresentar y discutir algunos de los resultados obtenidos se pretende ilustrar el daño a la salud originado por la represión en el país de origen, el desplazamiento y li instalación de los refugiados en el país receptor.

Para evaluar el estado de nutrición de un niño, el valor de una medición se relaciona con otro parámetro y luego se compara con los valores de una tabla o población de referencia. Los sistemas dv clasificación del estado de nutrición deben ir, necesariamentc, acompañados de la elección de un patrón de referencia. Dicha selección, por lo general, se plantea entre un patrón internacionalmente aceptado y uno elaborado a nivel local o regional. El uso de las tablas de National Center for Health Statistics (NCHS) ha sido recomendado por la OMS; esta recomendación se basa en el hecho de que llenan los requisitos sobre las características metodológicas deseables en un cuerpo de datos para ser usados como patrón de referencia. Por otro lado, el uso de estándares locales no permitc comparaciones internacionales; por tanto se eligió como patrón de referencia, el percentil 50 correspondiente a la edad del niño y se seleccionó el indicador antropométrico de peso para la edad, ya que tiene ciertas ventajas:

- El peso es algo fácilmente comprensible como tal para cualquier población. Se ha usado secularmente en el mercado y aun las poblaciones analfabetas entienden su valor.

- El peso es una medida sensible a las modificaciones agudas de la alimentación, mientras que la talla se afecta con la deficiencia crónica de ellos. Se pierde peso, no talla.

- La edad, aunque algunos autores afirman lo contrario, es un dato que con un poco de esfuerzo se puede conseguir, ya sea porque la madre conoce la fecha de nacimiento del niño, o bien, mediante actas 
o documentos que la indiquen, o relacionando el nacimiento del niño con eventos locales importantes de los cuales se puede obtener la fecha.

Para la clasificación del estado de nutrición en grados, se utilizó la descrita por Gómez; ésta se basa en el indicador antropométrico de peso para la edad. En esta clasificación, los criterios diagnósticos están expresados en el porcentaje que representa el peso encontrado con respecto a la media de la población de referencia. Esta clasificación se presenta en el siguiente cuadro.

CUADRO 3. Clasificación de la desnutrición en grados Gómez

\begin{tabular}{ll}
\hline Grados & Porcentaje \\
\hline Normal & 91 o más \\
I & $90-76$ \\
II & $75-61$ \\
III & 60 o menos \\
\hline
\end{tabular}

Bengoa añade que todos los casos con edema deben ser incluidos en el grado III de desnutrición.

Resumiendo, en los datos que a continuación se presentan, el indicador antropométrico utilizado es el peso para la edad; se clasifica el estado de nutrición de acuerdo a lo indicado por Gómez y Bengoa; y el valor de referencia utilizado fue el percentil 50 de las tablas del NCHS.

Para evaluar el estado de nutrición de los niños menores de 6 años fue necesario:

- Identificar a todos los niños menores de 6 años a partir de los censos elaborados por los representantes.

- Tomar y registrar su pesoy la fecha de nacimiento en diciembre de 1982 y en abril de 1983. El intervalo fue de 4 meses.

- Calcular la edad de los niños en meses.

- Obtener el porcentaje que representa el peso observado con respecto al patrón de referencia. 
- Agrupar a los niños de acuerdo a los siguientes grupos de edad en meses: 0 a 5,6 a 11,12 a 35 y 36 a 71 .

- Clasificar a los niños según su estado de nutrición y comparar los resultados obtenidos en los dos períodos.

- Identificar en las defunciones ocurridas en los menores de 6 años, el estado de nutrición que presentaban en el mes de diciembre de 1982.

Se comparó el estado de nutrición de los menores de 6 años en dos diferentes períodos: diciembre de 1982 , fecha en que comienzan las acciones del programa de alimentación complementaria, y en abril de 1983, a cuatro meses de su inicio.

Para el estudio de la mortalidad se tomaron dos períodos: el primero incluye las últimas dos semanas de noviembre y todo el mes de diciembre de 1982, yel segundo abarca desde enero hasta abril de 1983. El análisis de la mortalidad en el período enero-abril, se relaciona con el estado de nutrición observado en el mes de diciembre.

\section{Presentación y discusión de resultados}

Es de gran utilidad para el desarrollo y extensión de este tipo de programas, conocer el número y el porcentaje que constituye la población objetivo en la comunidad a la que va dirigido. En este caso la población vulnerable estaba integrada de la siguiente manera:

CUADRO 4. Población vulnerable, número y porcentaje del total de población.

\begin{tabular}{lcc}
\hline \multicolumn{1}{c}{ Grupo } & Número & Porcentaje \\
\hline Menores de 3 años & 586 & 15.0 \\
De 3 a 5 años & 498 & 12.7 \\
Embarazadas & 95 & 2.4 \\
Mujeres en lactancia & 310 & 7.9 \\
\hline TOTAL & 1498 & 38.0 \\
\hline
\end{tabular}


Esto significa que en una población con características similares, alrededor del $40 \%$ del total de los habitantes requiere de alimentación complementaria, cifra considerablemente mayor a la indicada por el Grupo Asesor de Naciones Unidas para Calorías y Proteínas, que señala: "Un $25 \%$ de la población total proporciona una estimación del número de personas que constituyen los grupos vulnerables y que necesitarán alimentación complementaria" (1977).

Este mismo grupo asesor indica que aproximadamente una tercera o una cuarta parte de las mujeres en edad fértil se encuentran en período de embarazo o lactancia. En el caso de los refugiados guatemaltecos, el $53.4 \%$ de las mujeres de 15 a 49 años se encontraba en esta situación. Esta proporción tan elevada se debe a la alta tasa de natalidad y a que la lactancia materna es, en apariencia, prolongada.

La respuesta por parte de los refugiados que permitieron que se les determinara el peso a sus niños, fue muy alta; en diciembre de 1982 acudieron 955 niños, de los cuales el $88.1 \%$ eran menores de 6 años. En abril este número fue de 1008 y el porcentaje de niños valorados se elevó al 93.0\%.

Muchos autores señalan que los estudios con estas características son difíciles, ya que pueden presentarse pérdidas en la muestra original, obien, que los datos relacionados con la edad y fecha de nacimiento del niño sean difíciles de conseguir o puedan ser erróneos. En este caso, esta aseveración no se aplica, del total de niños pesados en diciembre (1955) se consiguió la fecha de nacimiento de 928 (97.2\%). En abril se obtuvo la fecha de nacimiento en el $95.5 \%$ de los niños valorados. Del total de niños que tenían peso y fecha de nacimiento en diciembre, 216 (23.3\%) no acudieron a evaluarse en abril. Esto significa que solo 712 casos se incluyen en el análisis de la comparación del estado de nutrición, ya que contaron con ambos datos en los dos meses. En el mes de abril, de los 967 niños pesados, 255 (26.4\%) carecían de estos datos en diciembre.

Las causas por las cuales no acudieron en abril 216 niños registrados en el mes de diciembre, se ilustran en el siguiente cuadro. 
CUADRO 5. Causas por las que no acudieron a pesarse en abril los niños con datos en diciembre, número y porcentaje.

\begin{tabular}{lcc}
\hline \multicolumn{1}{c}{ Causas } & Número & Porcentaje \\
\hline Emigración & 109 & 50.5 \\
Desconocido & 64 & 29.6 \\
Defunción & 11 & 5.1 \\
\hline TOTAL & 216 & 100.0 \\
\hline
\end{tabular}

La migración interna entre los campamentos es bastante común. Los 109 casos señalados representaban el $11.7 \%$ del total de niños evaluados. Esto se manifestó también durante el mes de abril, ya que 124(12.8\%) del total de niños valorados habían llegado al campamento después de diciembre de 1982.

En el cuadro número 6 se presentan los resultados de la evaluación del estado de nutrición en diciembre y en abril, de todos los niños menores de 6 años que se incluyeron en el estudio. Los cuadros 7 , 8,9 y 10 ilustran estos datos en los 4 diferentes grupos de edad en que se subdividió a los menores de 6 años.

CUADRO 6. Estado de nutrición en diciembre y en abril de todos los niños menores de 6 años en diciembre, número y porcentaje.

\begin{tabular}{l|cc|cc}
\hline \multirow{2}{*}{ Clasificación } & \multicolumn{2}{|c|}{ Diciembre } & \multicolumn{2}{c}{ Abril } \\
\cline { 2 - 5 } & Número & $\%$ & Número & $\%$ \\
\hline Normal & 49 & 6.9 & 38 & 5.3 \\
Grado I & 257 & 36.1 & 249 & 35.0 \\
Grado II & 332 & 46.6 & 351 & 49.3 \\
Grado III & 74 & 10.4 & 74 & 10.4 \\
\hline TOTAL & 712 & 100.0 & 712 & 100.0 \\
X2 $=3.8$ N.S. & & & & \\
\hline
\end{tabular}


En el cuadro 6 se presenta el resultado de la clasificación del estado de nutrición en grados de todos los menores de 6 años que se incluyeron en el estudio. No se encontraron diferencias estadísticamente significativas en el estado de nutrición de un período a otro; los casos considerados como normales y con desnutrición grado I, son ligeramente mayores en el mes de diciembre que en abril, pero la desnutrición grado II se incrementa ligeramente $(2.7 \%)$. El número de desnutridos de tercer grado se mantiene igual, pero si comparamos el estado de nutrición de los niños en los diferentes grupos de edad que integran a los menores de 6 años, podremos comprender más acerca del proceso nutrición-desnutrición en esta población, así como identificar más claramente el impacto del Programa deAlimentación Complementaria a Grupos Vulnerables.

CUADRO 7. Estado de nutrición en diciembre y en abril de los niños de 0 a 5 meses de edad en diciembre, número y porcentaje.

\begin{tabular}{l|cc|cc}
\hline \multirow{2}{*}{ Clasificación } & \multicolumn{2}{|c|}{ Diciembre } & \multicolumn{2}{c}{ Abril } \\
\cline { 2 - 5 } & Número & $\%$ & Número & $\%$ \\
\hline Normal & 18 & 30.5 & 13 & 22.0 \\
Grado I & 21 & 35.6 & 17 & 28.8 \\
Grado II & 16 & 27.1 & 21 & 35.6 \\
Grado III & 4 & 6.8 & 8 & 13.6 \\
\hline TOTAL & 59 & 100.0 & 59 & 100.0 \\
X2 $=2.23$ N.S. & & & & \\
\hline
\end{tabular}

Con respecto al grupo de edad de 0 a 5 meses de edad (Cuadro 7) se puede observar que el porcentaje de niños considerados como normales y desnutridos de primer grado, disminuye en el segundo período, en cambio, se incrementa el número de niños que presentan desnutrición de segundo y tercer grado. El $33.9 \%$ se encontraban en desnutrición grado II y III en diciembre, esta proporción se eleva al $49.2 \%$ en abril; aunque esta diferencia no alcanza cifras estadísticamente significativas, indica una tendencia, ya que es consi- 
derable el aumento de desnutridos grado II y III de un período a otro. Es necesario destacar que se agrupó a los niños de acuerdo a su edad en diciembre, por lo que en abril tenían entre 4 y 9 meses de edad. Se puede pensar que es en esta etapa de la vida cuando la lactancia materna comienza a ser insuficiente. Llama la atención que cl porcentaje de niños considerados como normales en el mes de diciembre (30.5\%), es el más elevado y no se vuelve a presentar a ninguna otra edad en los períodos considerados. Esta proporción contra la desnutrición se la podemos atribuir a la lactancia materna, práctica llevada a cabo por la mayor parte de las mujeres.

CUADRO 8. Estado de nutrición en diciembre y en abril de los niños de 6 a 11 meses de edad en diciembre, número y porcentaje.

\begin{tabular}{l|cr|cr}
\hline \multirow{2}{*}{ Clasificación } & \multicolumn{2}{|c|}{ Diciembre } & \multicolumn{2}{c}{ Abril } \\
\cline { 2 - 5 } & Número & $\%$ & Número & $\%$ \\
\hline Normal & 4 & 4.8 & 0 & 0.0 \\
Grado I & 28 & 32.1 & 17 & 20.0 \\
Grado II & 42 & 50.0 & 55 & 64.7 \\
Grado III & 11 & 13.1 & 13 & 15.3 \\
& & & & \\
TOTAL & 85 & 100.0 & 85 & 100.0 \\
X2 = 5.62 P >0.05 & & & & \\
\hline
\end{tabular}

$\mathrm{Al}$ analizar el cuadro 8 se observa que en el grupo de niños que en el primer período tenían entre 6 y 11 meses de edad, los casos considerados como normales pasan a ser desnutridos. El porcentaje de niños con desnutrición de segundo y tercer grado pasa del $63.1 \%$ en diciembre al $80.0 \%$ en abril; este incremento de 15 casos constituye el $16.9 \%$. La incidencia de desnutrición de segundo y tercer grado de un período a otro es estadísticamente significativa a un nivel de confianza del 95\%; la proporción de niños con desnutrición grado II y III que presenta este grupo en el mes de abril, es la más elevada de todos los grupos en los dos períodos; es probable que este incrementotan notable de niños desnutridos se deba a lo que han señalado varios autores que 
cstablecen que a esta edad no sólo se acentúa la insuficiencia de la lactancia materna, sino que aumentan las diarreas y otras infecciones instalando el efecto sinérgico de la desnutrición-infección-desnutrición. Esto explica el hecho de que no se encontraron niños normales en el mes de abril en este grupo de edad. Cabe destacar que no se encontraron desnutridos de tipo kwashiorkor en los menores de un año.

CUADRO 9. Estado de nutrición en diciembre y en abril de los niños de 12 a 35 meses de edad en diciembre, número y porcentaje.

\begin{tabular}{l|rr|rr}
\hline \multirow{2}{*}{ Clasificación } & \multicolumn{2}{|c|}{ Diciembre } & \multicolumn{2}{|c}{ Abril } \\
\cline { 2 - 5 } & Número & $\%$ & Número & $\%$ \\
\hline Normal & 9 & 3.5 & 9 & 3.5 \\
Grado I & 79 & 30.8 & 87 & 34.0 \\
Grado II & 127 & 49.7 & 127 & 49.6 \\
Grado III & 41 & 16.0 & 33 & 12.9 \\
\hline TOTAL & 259 & 100.0 & 256 & 100.0 \\
X2 $=2.10$ N.S. & & & & \\
\hline
\end{tabular}

En el grupo que muestra el cuadro 9, el resultado de la evaluación del estado de nutrición es bastante semejante, la diferencia de un período a otro no es significativa. La desnutrición de primer grado aumenta en la misma proporción en la que disminuye la de tercergrado, esto se puede deber a que en abril no se encontraron niños con edema; los que tenían edema en diciembre, 10 casos $(2.9 \%)$ para este grupo de edad, se clasificaron como desnutridos grado III. Se sabe que los niños con desnutrición de tipo kwashiorkor, por ser un proceso agudo, pueden no haber reducido su talla y mantener parte de su tejido graso. Por lo tanto, al desaparecer el edema por efecto de la recuperación, aunque disminuye su peso, la relación peso-edad puede ser más elevada que la de los niños con desnutrición de tipo marasmático, originada por un proceso crónico.A partir de esta observación se puede concluir que el programa de atención nutricional a grupos vulnerables, 
a 4 meses de su inicio, ejerció más su impacto sobre la desnutrición de tipo agudo que sobre la de tipo crónico.

CUADRO 10. Estado de nutrición en diciembre y en abril de los niños de 36 a 71 meses de edad en diciembre, número y porcentaje.

\begin{tabular}{l|cr|cr}
\hline \multirow{2}{*}{ Clasificación } & \multicolumn{2}{|c|}{ Diciembre } & \multicolumn{2}{c}{ Abril } \\
\cline { 2 - 5 } & Número & $\%$ & Número & $\%$ \\
\hline Normal & 18 & 5.8 & 16 & 5.1 \\
Grado I & 129 & 41.3 & 128 & 41.0 \\
Grado II & 147 & 47.1 & 148 & 47.5 \\
Grado III & 18 & 5.8 & 20 & 6.4 \\
\hline TOTAL & 312 & 100.0 & 312 & 100.0 \\
X2 $=0.25$ N.S. & & & & \\
\hline
\end{tabular}

Como en el grupo anterior, el estado de nutrición en ambos períodos es muy similar en los niños considerados entre 36 y 71 meses de edad (Cuadro 10). Las diferencias encontradas no son estadísticamente significativas. La cantidad de desnutridos de tercer grado es la menor de todos los grupos de edad estudiados. 13 niños (3.3\%) presentaban edema durante el mes de diciembre; para el mes de abril no se encontró a ningún niño con edema.

En el período que comprende desde las últimas dos semanas del mes de noviembre hasta el final del mes de abril, ocurrieron $\mathbf{1 1 0}$ defunciones, 82 de éstas (74.5\%) ocurrieron en los menores de 6 años. Si este período lo dividimos en dos partes, el primero que abarque las dos últimas semanas del mes de noviembre y todo diciembre (6 semanas), y el otro que incluya los meses de enero, febrero, marzo y abril (16 semanas), podemos observar lo siguiente: que la mortalidad general es mucho más elevada en el primer período con un total de 67 casos en comparación con 43 defunciones en el segundo período; que la mortalidad en los menores de 3 años en el primer período fue de 28 casos y en el segundo fue de 21 ; en los niños de 3 a 5 años ésta 
fue en el primer período de 22 casos y en el segundo de 11 . En los menores de 6 años, las diferencias en la mortalidad ocurridas en el período noviembre-diciembre con respecto al período enero-abril son estadísticamente significativas $(X 2=7.22, \mathrm{p}>0.01)$. Esto permite identificar que uno de losbeneficios del programa de alimentación complementaria es la disminución de la mortalidad en los menores de 6 años.

En el grupo de niños de 6 a 11 meses de edad la incidencia de desnutrición de segundoy tercer gradose incrementa en el mes de abril; sin embargo, es en este grupo de edad donde las defunciones ocurren en menor proporción; esto indica que, si bien el programa de alimentación complementaria no logra mejorar el estado de nutrición, ejerce suimpacto sobre la mortalidad; esto se explica, en parte, porque el programa contempla mayor vigilancia y atención nutricional a este grupo de edad.

El análisis de la mortalidad que ocurrió en los niños evaluados durante el mes de diciembre nos dice que ocurrieron 32 defunciones durante 4 meses; de éstas, 3 ocurrieron en los niños considerados como normales, 5 en los que presentaban desnutrición de primer grado, 12 en los niños con desnutrición grado II y 12 en aquellos que en diciembre se los consideró como desnutridos de tercer grado. Se hareportado con frecuencia que las tasas de mortalidad son más o menos constantes en diversos niveles de desnutrición, pero que aumentan rápidamente cuando se alcanza un nivel particular. Este nivel coincide con el diagnóstico señalado por Gómez para delimitar la desnutrición de tercer grado; el presente estudio corrobora este hecho. La relación que guarda la mortalidad en los niños con desnutrición de tercer grado con respecto a los de primero y segundo es de $1: 7.3$ y de $1: 4$ respectivamente, $\mathrm{y}$ es estadísticamente significativa.

El análisis de la mortalidad por semana, que incluye las últimas dos del mes de noviembre de 1982 hasta el 30 de abril de 1983, muestra un descenso de la misma. Si bien se ha descrito que este fenómeno se observa con el transcurso del tiempo, en el nuevo asentamiento es demasiado notorio como para adjudicarlo en forma exclusiva a este factor. Por otra parte, esta tendencia decreciente se interrumpe en las semanas 13, 14 y 15 que corresponden a las últimas dos semanas defebrero y la primera de marzo; esto coincidió con la falta de alimentos para el programa. 


\section{Reflexiones a manera de discusión}

No hay diferencias estadísticamente significativas en el estado dc nutrición de los menores de 6 años de un período a otro; sin embargo, el análisis del estado de nutrición por grupos de edad indica que cl porcentaje de niños considerados como normales en el grupo de edad de 0 a 5 meses encontrado en el mes de diciembre, es el más elevado y no se vuelve a presentar a ninguna otra edad en los períodos considerados. La prevalencia de desnutrición de tercer grado encontrada en el mes de diciembre en los niños de 12 a 35 meses de edad es la mayor de todos los grupos en ambos períodos. La incidencia de desnutrición de segundo y tercer grado es significativamente mayor en los niños de 6 a 11 meses de edad.

El indicador antropométrico utilizado (peso para la edad) para la evaluación del estado de nutrición resultó adecuado, ya que la población conoce la fecha de nacimiento de los niños, y el peso es una medida fácil de obtener. Este indicador antropométrico, así como los criterios diagnósticos utilizados, fueron adecuados para identificar a los niños con mayor riesgo de mortalidad.

Los resultados sugieren que el impacto del Programa de Alimentación Complementaria a Grupos Vulnerables, a 4 meses de su inicio, es sobre la mortalidad y más específicamente en la de los menores de 3 años y sobre la desnutrición de tipo agudo.

El programa llegóa operar en 9 campamentos, los que sumaban una población total de 19,000 habitantes, de los cuales el $38 \%(7,220)$ correspondían a la población vulnerable. Es importante señalar que existió enlace con un segundo nivel de atención, localizado en el Hospital de Comitán y en el Centro de Recuperación Nutricional en la misma ciudad; sin embargo, el manejo del niño desnutrido es delicado, largo y costoso. Por lo tanto, el concepto de riesgo es de fundamental importancia en todas las actividades del primer nivel de atención, que en este caso se ubica en los mismos campamentos a través del Programa de Alimentación Complementaria y de la clínica local. La comunidad, con la capacitación adecuada, toma las decisiones pertinentes con base en el criterio general de la asignación de riesgos: "Dar más al que más lo necesita". 
En el caso de los refugiados guatemaltecos, la participación de la comunidad fue la que hizo posible la realización de todas las actividades del programa. Esta participación estaba determinada por las condiciones de sobrevivencia a la que estaban expuestos, por lo tanto, se considera importante señalar que el proyecto tiene características particulares que demandan un elevado grado de organización social y de tiempo disponible. Este fue un proyecto que respondió acertadamente a las características de una situación de emergencia en la población de refugiados guatemaltecos localizados en el estado de Chiapas, México. Sin embargo, las condiciones críticas tienden a estabilizarse con el transcurso del tiempo por lo que las acciones asistenciales deben disminuir paulatinamente. 


\section{B I B L I O G R A F I A}

ATENCION PRIMARIA EN SALUD. 1978. Informe de la conferencia internacional de salud. Alma-Ata, URSS. Septiembre.

BENGOA J. 1970 Recent tends in the public health aspects of protein calorie malnutrition. WHO. Chronicle.

COMPENDIO DE ESTADISTICAS VITALES DE MEXICO, 1977. 1981. S.S.A. México, 1981.

CHAVEZ A. 1979. Nutrición y desarrollo infantil. Ed. Interamericana, México.

DE VILLE C. et al. 1983. "El manejo de las emergencias nutricionales en grandes poblaciones". OPS/OMS. En: Publicación científica. No. 444. Washington.

GOMEZ F. 1946. Desnutrición. Boletín Médico del Hospital Infantil. México.

GOMEZ F., et al. 1956 "Mortality in Second and Third Degree Malnutrition. Journal of tropical pediatrics in Africa child health.

GRAITEER P. 1981. Basic assessment of nutritional status in emergencies. International Disaster Institute. New York.

GRUPO ASESOR DEL SISTEMA DE NACIONES UNIDAS SOBRE PROTEINAS Y CALORIAS. 1977. Guia para las operaciones de socorro con viveres y medidas de protección de la salud en casos de desastre. FAO, OMS, UNICEF, BM, ONU, New York.

HERNANDEZ M., et al.1983. Valor nutritivo de los alimentos mexicanos. Publicaciones de la División de Nutrición. L-12.9a. ed. Instituto Nacional de Nutrición, México.

MATA L. 1978. The nature of the nutrition problem in nutrition planning. Science and Technology Press, London. 1983. Measuring change in nutritional status. WHO. Ginebra.

MORLEY D. 1977. Prioridades en la salud infantil. Ed Pax. México.

NATIONAL CENTER FOR HEALTHSTATISTICS. 1976. Monthly and vital statistics report. 25 . Suplement.

PUFFER R., Serrano C. 1975. "Características de la mortalidad en la niñez”. OPS. Publicación científica No. 262. Washington.

SCRIMSHAW, N. 1984. "Significance of interactions of nutrition and infection in Children". Textbook of pediatric nutrition. Raven Press. New York. 
UNITED NATIONS HIGH COMMISSIONER FOR REFUGEES. 1982. Handbook for emergencies. Ginebra.

VIGILANCIA DEL CRECIMIENTO. 1980. American Public Health Association. Programas Internacionales en Salud. UNICEF. México.

VITERI F. 1981. "Primary protein-calorie malnutrition". Textbook of pediatric nutrition. Raven Press. New York. 